\title{
Investigation of the Optimal Parameters in Hydrothermal Method for the Synthesis of ZnO Nanorods
}

\author{
Ying-Chung Chen, ${ }^{1}$ Huan-Yi Cheng, ${ }^{1}$ Cheng-Fu Yang, ${ }^{2}$ and Yuan-Tai Hsieh ${ }^{3}$ \\ ${ }^{1}$ Department of Electrical Engineering, National Sun Yat-Sen University, Kaohsiung 80424, Taiwan \\ ${ }^{2}$ Department of Chemical and Materials Engineering, National University of Kaohsiung, Kaohsiung 81147, Taiwan \\ ${ }^{3}$ Department of Electronic Engineering, Southern Taiwan University, Tainan 71005, Taiwan
}

Correspondence should be addressed to Cheng-Fu Yang; cfyang@nuk.edu.tw

Received 7 May 2014; Accepted 16 June 2014; Published 25 June 2014

Academic Editor: Teen-Hang Meen

Copyright (C) 2014 Ying-Chung Chen et al. This is an open access article distributed under the Creative Commons Attribution License, which permits unrestricted use, distribution, and reproduction in any medium, provided the original work is properly cited.

\begin{abstract}
We investigated a two-step method to deposit the $\mathrm{ZnO}$-based nanostructure films, including nanorods and nanoflowers. In the first step, sputtering method was used to deposit the $\mathrm{ZnO}$ films on $\mathrm{SiO}_{2} / \mathrm{Si}$ substrates as the seed layer. In the second step, $\mathrm{Zn}\left(\mathrm{NO}_{3}\right)_{2}-$ $6 \mathrm{H}_{2} \mathrm{O}$ and $\mathrm{C}_{6} \mathrm{H}_{12} \mathrm{~N}_{4}$ were used as precursors and hydrothermal process was used as the method to synthesize the $\mathrm{ZnO}$ films. After that, the $\mathrm{ZnO}$ films were measured by an X-ray diffraction pattern and a FESEM to analyze their crystallization and morphology. We had found that the $\mathrm{ZnO}$ films had three different morphologies synthesized on $\mathrm{ZnO} / \mathrm{SiO}_{2} / \mathrm{Si}$ substrates, including irregularplate structure films, nanorod films, and beautiful chrysanthemum-like clusters (nanoflower films). We would prove that the face direction of $\mathrm{ZnO} / \mathrm{SiO}_{2} / \mathrm{Si}$ substrates in the hydrothermal bottle and deposition time were two important factors to influence the synthesized results of the $\mathrm{ZnO}$ films.
\end{abstract}

\section{Introduction}

Transparent conducting oxide (TCO) films based on zinc oxide $(\mathrm{ZnO})$ are promising candidates for applications in various optoelectronic devices. However, $\mathrm{ZnO}$-based films present a lot of advantages such as higher transparency in infrared region and high chemical stability under the hydrogen plasma as compared to tin-doped indium oxide (ITO). For that, transparent conducting $\mathrm{ZnO}$-based films have already been extensively used in solar cells, lightemitting diodes, and liquid crystal displays as a substitute for ITO [1]. ZnO nanorods have attracted much attention of researchers due to their various applications such as solar cells [2], light-emitting diodes [3], and super hydrophobic surfaces [4]. $\mathrm{ZnO}$ nanorods are also considered as a promising material of gas sensors because of its high electrochemical stability, nontoxicity, suitability to doping, and low material cost [5]. The sensing characteristics of a sensor depend on the shape and dimensionality of the sensing material a lot, so that multiplicate $\mathrm{ZnO}$ nanostructures have been synthesized and studied in the past decade. Those researches have shown that one-dimensional (1D) $\mathrm{ZnO}$ nanostructures possess a large surface-to-volume ratio, which can absorb more tested molecules on the surface and have high gas-sensing efficiency [5-7].

Up to now, $1 \mathrm{D} \mathrm{ZnO}$-based nanotubes, nanowires, nanorods, and nanotetrapods have been synthesized by various physical and chemical methods and used to fabricate gas sensors. Synthesis of the $\mathrm{ZnO}$ nanorods based on vapor phase deposition, such as metal-organic chemical vapor deposition, vapor-liquid-solid reaction, vapor-solid reaction, chemical vapor deposition, and pulsed laser deposition are expensive methods because of the sophisticated equipment or high temperature required [8]. In contrast to the above growth techniques, the aqueous solution growth method can be a simple and cost-effective technique because it has no drawbacks of expensive apparatus, rigorous condition, complex process, low yield, and high temperature needed. Recently, a hydrothermal method has also been developed to fabricate $1 \mathrm{D} \mathrm{ZnO}$ nanostructures. Jiaqiang et al. had 
prepared $\mathrm{ZnO}$ nanorods by a hydrothermal process with cetyltrimethyl ammonium bromide and zinc powder at $182^{\circ} \mathrm{C}$ [9]; Li et al. had synthesized ultralong $\mathrm{ZnO}$ nanowires by a hydrothermal reaction of $\mathrm{Zn}$ foil and aqueous $\mathrm{Na}_{2} \mathrm{C}_{2} \mathrm{O}_{4}$ solution at $140^{\circ} \mathrm{C}$ [6]; Kim and Yong had synthesized $\mathrm{ZnO}$ nanorod-bundle powders by a hydrothermal reaction using zinc chloride and ammonium hydroxide solution at $150^{\circ} \mathrm{C}$ [7]. Those results prove that the hydrothermal method provides a convenient and low cost route for the construction of rod- or wire-typed $\mathrm{ZnO}$ nanostructures. Herein, we used $\mathrm{SiO}_{2} / \mathrm{Si}$ as substrates and investigated a two-step method to find a simple process for growing $\mathrm{ZnO}$-based nanorods. In the first step, the $\mathrm{ZnO}$ seed layer was deposited using sputter method. In the second step, we used $\mathrm{Zn}\left(\mathrm{NO}_{3}\right)_{2}-6 \mathrm{H}_{2} \mathrm{O}$ and $\mathrm{C}_{6} \mathrm{H}_{12} \mathrm{~N}_{4}$ (Hexamethylenetetramine, HMTA) as precursors to develop a low-temperature hydrothermal route $\left(\right.$ at $\left.100^{\circ} \mathrm{C}\right)$ for synthesizing the nanorod-typed $\mathrm{ZnO}$ nanostructures. We would show that faces' direction of $\mathrm{ZnO} / \mathrm{SiO}_{2} / \mathrm{Si}$ substrates in the hydrothermal bottle and deposition time were two important factors to grow the $\mathrm{ZnO}$ nanorods.

\section{Experimental}

$\mathrm{ZnO}$ powder was mixed with polyvinylalcohol (PVA) as binder, and then the mixed powder was uniaxially pressed into pellets of $5 \mathrm{~mm}$ thickness and $54 \mathrm{~mm}$ diameter using a steel die. After debindering, the $\mathrm{ZnO}$ pellets were sintered at $1200^{\circ} \mathrm{C}$ for $2 \mathrm{~h}$. $\mathrm{SiO}_{2} / \mathrm{Si}$ substrates with an area of $2 \times$ $2 \mathrm{~cm}^{2}$ were cleaned ultrasonically with isopropyl alcohol (IPA) and deionized (DI) water and then dried under a blown nitrogen gas. Our growth procedure for $\mathrm{ZnO}$-based nanostructures consisted of two steps. At the first step, $\mathrm{ZnO}$ targets were used to deposit $\mathrm{ZnO}$ films with a thickness of $\sim 300 \mathrm{~nm}$ by sputtering deposition technique to form the $\mathrm{ZnO} / \mathrm{SiO}_{2} / \mathrm{Si}$ substrates. $\mathrm{ZnO}$ films were subsequently used as seed layer for the growth of $\mathrm{ZnO}$ nanostructures. The deposition parameters for seed layer were RF power of $85 \mathrm{~W}$, working pressure of $15 \times 10^{-3}$ Torr in pure $\mathrm{Ar}$ (99.99\%) ambient, deposition at room temperature (RT), and the deposition time of $30 \mathrm{~min}$, respectively. In the second step, $\mathrm{ZnO}$ nanostructures were grown on seed-deposition $\mathrm{ZnO} / \mathrm{SiO}_{2} / \mathrm{Si}$ substrates from an equimolar aqueous solution of $\mathrm{Zn}\left(\mathrm{NO}_{3}\right)_{2}-6 \mathrm{H}_{2} \mathrm{O}$ (99.9\% purity) and $\mathrm{C}_{6} \mathrm{H}_{12} \mathrm{~N}_{4}(99.9 \%$ purity, Hexamethylenetetramine, HMTA) in deionized water [10-12]. In order to fabricate $\mathrm{ZnO}$ nanorods, $\mathrm{Zn}\left(\mathrm{NO}_{3}\right)_{2}-$ $6 \mathrm{H}_{2} \mathrm{O}$ and $\mathrm{C}_{6} \mathrm{H}_{12} \mathrm{~N}_{4}$ were used as reagents, the diluted solution with concentration of $0.1 \mathrm{M}$ in DI water, and volume of DI water was $20 \mathrm{~g}$. After mixing at $65^{\circ} \mathrm{C}$ for $40 \mathrm{~min}$ the diluted solution was put into a bottle and the $\mathrm{ZnO}$ nanostructures were synthesized on the seed $\mathrm{ZnO} / \mathrm{SiO}_{2} / \mathrm{Si}$ layer by using hydrothermal process at $100^{\circ} \mathrm{C}$ for $1 \mathrm{~h}, 3 \mathrm{~h}$, and $5 \mathrm{~h}$, respectively. The sketch of the experimental set for growing $\mathrm{ZnO}$ nanostructure films was shown in Figure 1, two different directions were compared in this study, and $\mathrm{ZnO}$ films were deposited on both up and down faces of $\mathrm{ZnO} / \mathrm{SiO}_{2} / \mathrm{Si}$ substrates. Surface morphology of $\mathrm{ZnO}$ films was observed using a field emission scanning electron microscopy (FESEM), and their crystalline structures were

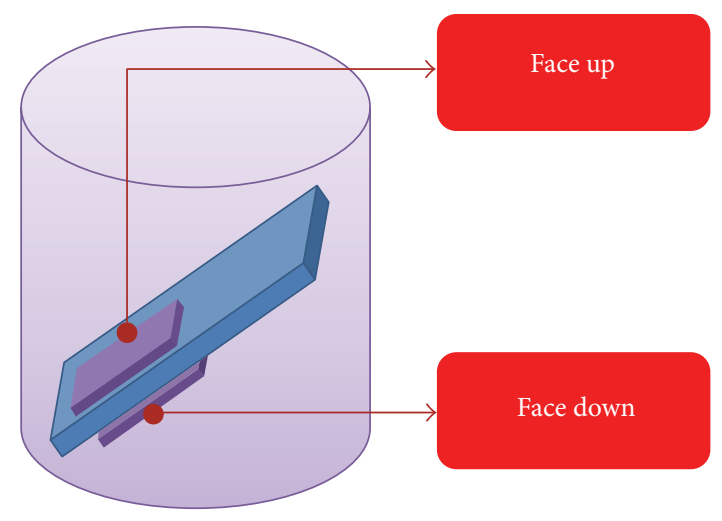

Figure 1: Structure for growing nanostructure $\mathrm{ZnO}$ films.

measured using X-ray diffraction (XRD) patterns with $\mathrm{Cu} \mathrm{K} \alpha$ radiation $(\lambda=1.5418 \AA)$.

\section{Results and Discussion}

To investigate the general morphologies of hydrothermaldeposited $\mathrm{ZnO}$ nanostructures, the synthesized products are first examined by FESEM and demonstrated in Figure 2 under lower magnifications. The hydrothermal process is based on the formation of solid phase from a solution, which involves two steps as nucleation and growth [12]. At first in the nucleation process, the clusters of molecules formed undergo rapid decomposition $\left(\mathrm{Zn}\left(\mathrm{NO}_{3}\right)_{2}-6 \mathrm{H}_{2} \mathrm{O}\right.$ is used as source) and particles combine to grow up on the substrate surface of the $\mathrm{ZnO}$ seed layer by nonheterogeneous reactions. Figure 2(a) shows the down-face morphology of the $1 \mathrm{~h}$ deposited $\mathrm{ZnO}$ films; there are no nanorods or nanoflowers that appeared on the $\mathrm{ZnO} / \mathrm{SiO}_{2} / \mathrm{Si}$ substrates in the first $1 \mathrm{~h}$ growth and only irregular-plate structure films were observed, which was identical to the up-face morphology. In the past, Liu et al. explained that the different morphology of the deposited $\mathrm{ZnO}$ films on different substrates should be related to the lattice structure and defects on the substrates' surfaces, which were key factors for chemical adsorption and subsequent nucleation and growth [12]. However, we will show that the deposition time and the face of substrates are two important factors to synthesize the $\mathrm{ZnO}$ nanorods on $\mathrm{ZnO} / \mathrm{SiO}_{2} / \mathrm{Si}$ substrates.

From the obtained FESEM observations in Figure 2(b), it is confirmed that as deposition time was $3 \mathrm{~h}$, the synthesized products were only $\mathrm{ZnO}$ nanorods with a diameter ranging from 65 to $200 \mathrm{~nm}$, grown in very large quantity, and the irregular-plate structure shown in Figure 2(a) was not observed. As the $\mathrm{ZnO}$ nanorods are synthesized in large quantity and densely populated, hence it is seen that many nanorods are not joined with each other at each side of the nanorods, which suggests that the $\mathrm{ZnO}$ nanorods can have enough space to detect gas and act as a sensor. When deposition time was increased to $5 \mathrm{~h}$, as Figure 2(c) shows, the synthesized products were not only nanorods, but also beautiful chrysanthemum- (flower-) like clusters grown above the nanorods in very large quantity. The flower-like 


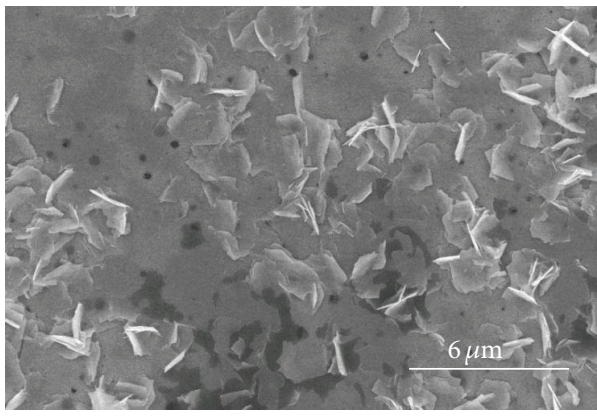

(a)

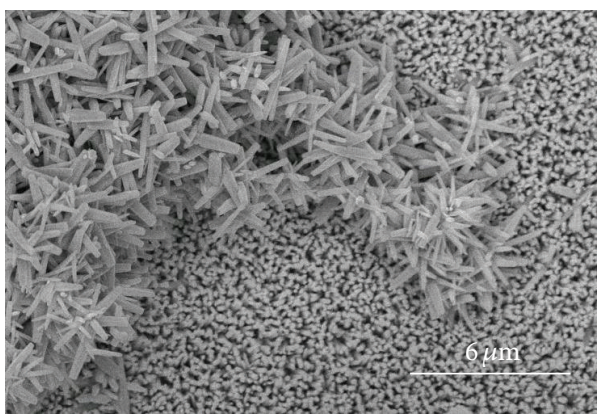

(c)

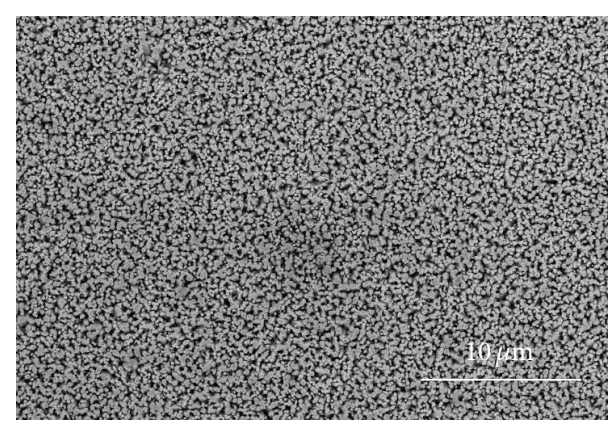

(b)

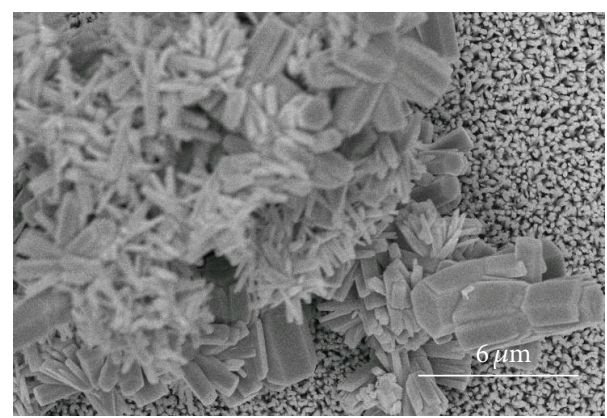

(d)

FIGURE 2: Surface morphologies of the deposited $\mathrm{ZnO}$ films synthesized at different faces and time and under different magnifications. Down face (a) $1 \mathrm{~h}$, (b) $3 \mathrm{~h}$, and (c) $5 \mathrm{~h}$; up face (d) $5 \mathrm{~h}$, respectively.

microstructures also consist of nanorods with a diameter ranging from 200 to $350 \mathrm{~nm}$ and length of $1.5-3 \mu \mathrm{m}$, and the flower-like architectures become dominant with substrate coverage of about $50 \%$. However, as the surface morphology in up face was observed, as Figure 2(d) shows, the size of the flower-like nanostructures was not uniform, while a few of the large rods with different diameters and lengths were also present. The flower-like and large-rod architectures developed further and became dominant with substrate coverage of about $80 \%$. Those results suggest that the $\mathrm{ZnO}$ deposition rate of up-face substrates is quicker than that of down-face substrates and $3 \mathrm{~h}$ is the optimal time to grow the $\mathrm{ZnO}$ nanorods as the gas sensors.

The XRD results in Figure 3 reveal that all the $\mathrm{ZnO}$ deposited films were of hexagonal wurtzite structure, and the three patterns of the $\mathrm{ZnO}$-deposited films were in agreement with but different from the diffraction data from standard card (JCPDS 36-1451). The mainly crystalline peak of $\mathrm{ZnO}$ in JCPDS 36-1451 is (101), which is located around $2 \theta \sim 36.25^{\circ}$. By comparison, the stronger intensity of (002) diffraction peak was found in Figure 3 for all deposited $\mathrm{ZnO}$ films, suggesting that all the films exist in high $c$-axis orientation. Accordingly, the tendency of c-orientation (200) peak was increased as the deposition time increased from $1 \mathrm{~h}$ to $3 \mathrm{~h}$. The increase of the full width at half maximum (FWHM) values of (200) peak indicates that the crystallization of $\mathrm{ZnO}$ films increases as the synthesized time increases.

Results in Figure 3 indicate that $1 \mathrm{~h}$ deposited $\mathrm{ZnO}$ films had a (002) peak and two weak (100) and (110) peaks; $3 \mathrm{~h}$ deposited $\mathrm{ZnO}$ films only had a strong (002) peak; and $5 \mathrm{~h}$

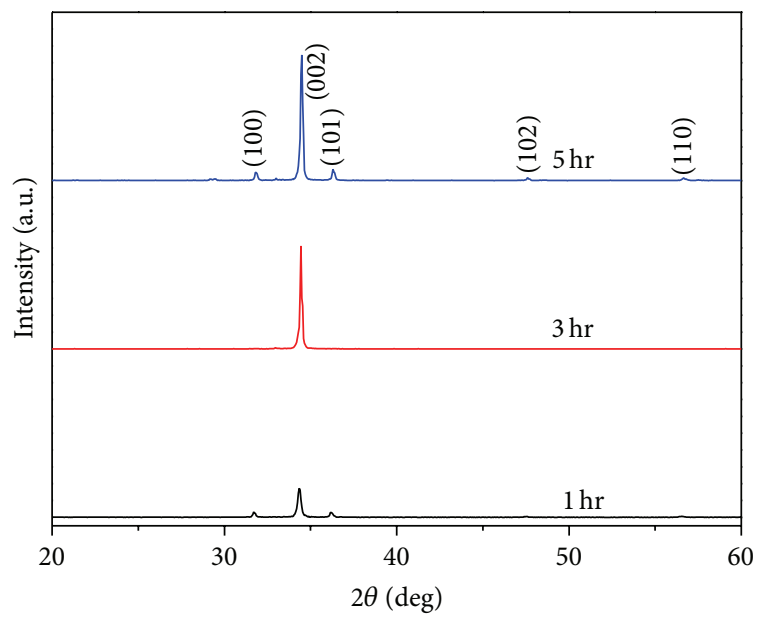

FIGURE 3: XRD patterns of the down-face $\mathrm{ZnO}$ films synthesized at different deposition time.

deposited $\mathrm{ZnO}$ films had a strong (002) peak and two weak (100) and (110) peaks. The (002), (100), and (110) peaks are preferred orientation with the $c$-axis perpendicular to the substrate. Those results illustrate that the diffraction data on the surface match the morphology as well as crystal orientation of the resultant films. An energy dispersive spectroscopic (EDS) analysis of the $\mathrm{ZnO}$ films in Figure 4 (up-face and deposition time was $3 \mathrm{~h}$ ) shows that the products were composed mainly of $\mathrm{Zn}$ and $\mathrm{O}$ elements, consistent with 


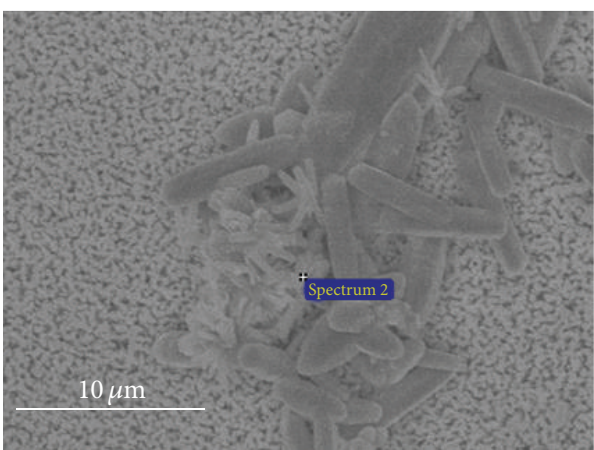

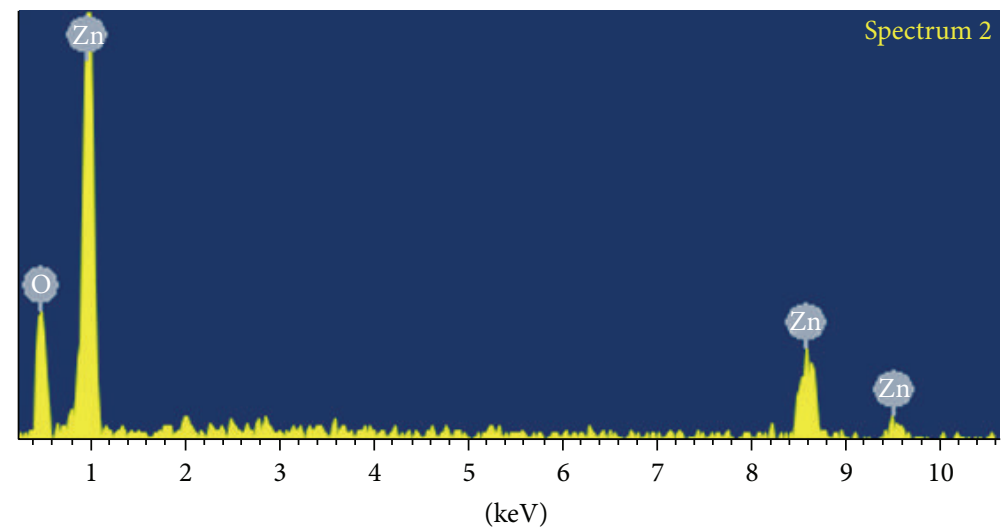

(b)

FIGURE 4: EDS analysis of the up-face $\mathrm{ZnO}$ films synthesized at $3 \mathrm{~h}$.

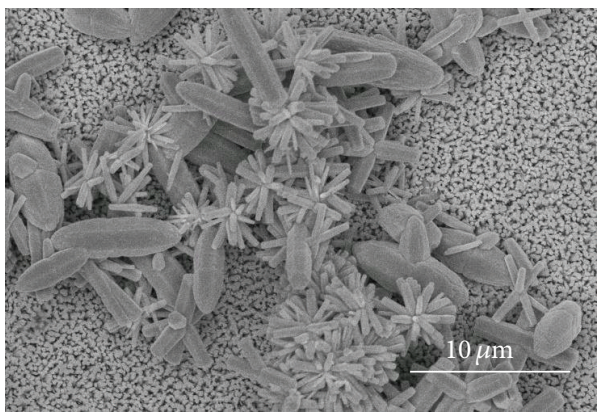

(a)

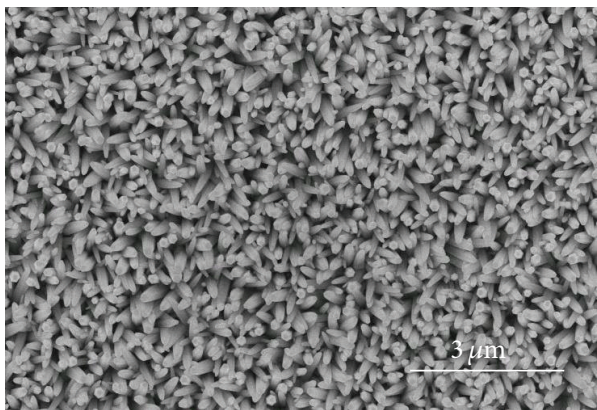

(c)

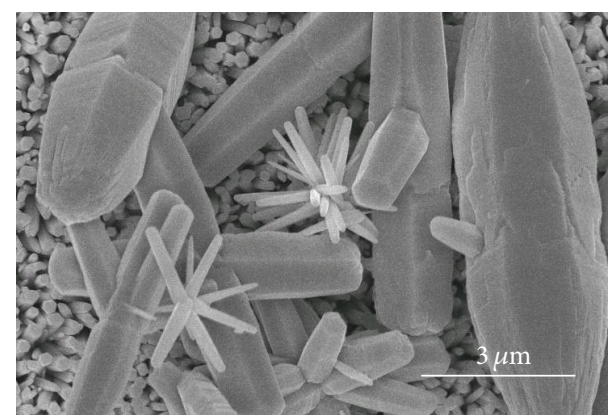

(b)

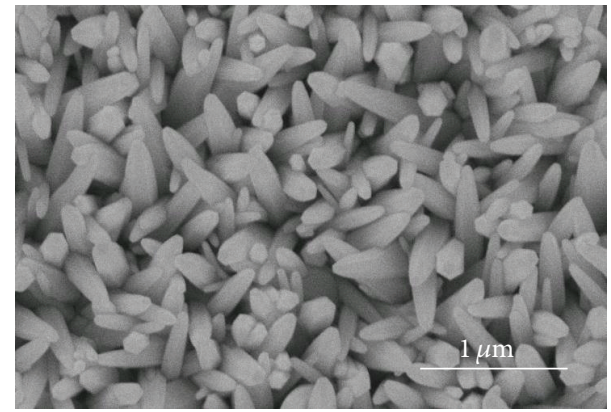

(d)

FIGURE 5: Surface morphologies of the ZnO films synthesized at different faces and different magnifications; the deposition time was $3 \mathrm{~h}$. Up face with (a) lower magnification and (b) higher magnification; down face with (c) lower magnification and (d) higher magnification, respectively.

the results of XRD in Figure 3. The results in Figures 3 and 4 illustrate that the different lattice mismatches and defects affect the morphology as well as crystal orientation of the deposited $\mathrm{ZnO}$ films.

To investigate the general morphologies of as-synthesized $\mathrm{ZnO}$ nanorods and nanoflowers, the synthesized products are examined by FESEM and demonstrated in lower and higher magnification FESEM images, and the results are shown in Figure 5. The SEM images in Figures 5(a) and 5(b) clearly show that the up-face surfaces of the $3 \mathrm{~h}$ deposited
$\mathrm{ZnO} / \mathrm{SiO}_{2} / \mathrm{Si}$ substrates had been coated with non-uniformsized $\mathrm{ZnO}$ nanorods, nanoflowers, and large hexagonal bars. The SEM images in Figures 5(c) and 5(d) clearly show that the down-face surfaces of the $3 \mathrm{~h}$ deposited $\mathrm{ZnO} / \mathrm{SiO}_{2} / \mathrm{Si}$ substrates had been coated with uniform-sized and quasioriented $\mathrm{ZnO}$ nanorods. As we know, crystallization exists in two different successive stages: nucleation and crystal growth. The interaction between these two steps determines the crystal characteristics, including size, distribution, and morphology of the crystals. When the solutions are used to 


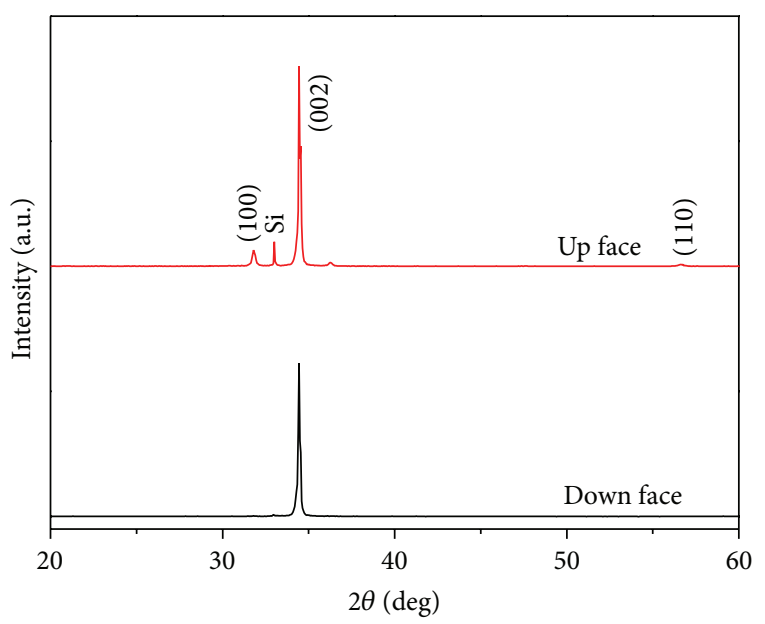

FIGURE 6: XRD patterns of the $\mathrm{ZnO}$ films synthesized at different faces; the deposition time was $3 \mathrm{~h}$.

synthesize or deposit films, there are two different nucleation mechanisms in the solution: heterogeneous nucleation and homogenous nucleation [13]. Homogenous nucleation takes place when primary nucleation proceeds in a nucleation free solution; this is when the solution contains no foreign particles. Heterogeneous nucleation takes place if primary nucleation proceeds when foreign particles are present in the solution.

The reason for the different morphology of the synthesized $\mathrm{ZnO}$ films obtained on the two faces should be related to the different nucleation mechanisms in the solution. In our case, the growth of $\mathrm{ZnO}$ films on $\mathrm{ZnO} / \mathrm{SiO}_{2} / \mathrm{Si}$ substrates at different faces was controlled by the two nucleation mechanisms. Li et al. have successfully grown large scale arrays of $\mathrm{ZnO}$ nanorods on zinc foil without the assistance of any template, oxidant, or coating of metal oxide layers, simply by dipping the foil into a $25 \%$ aqueous solution of ammonia $\left(\mathrm{NH}_{4} \mathrm{OH}\right)$ and heating at a temperature $80^{\circ} \mathrm{C}$ in a Teflon-lined stainless steel autoclave [14]. They prepared four different samples by varying the concentration of ammonia in an $80 \mathrm{~mL}$ growth bath and the growth duration. They found that the thickness, density, and morphology of the $\mathrm{ZnO}$ nanorods are affected by the alkalinity of the solution in the growth bath. However, in this study we prove that with the addition of $\mathrm{ZnO}$ films as seed layer on $\mathrm{SiO}_{2} / \mathrm{Si}$ substrates we can synthesize the nanorods and nanoflowers at $100^{\circ} \mathrm{C}$. Those results also suggest that we can control the number of the irregular-plate type $\mathrm{ZnO}, \mathrm{ZnO}$ nanorods, and $\mathrm{ZnO}$ nanoflowers on $2 \times 2 \mathrm{~cm}^{2}$ sample by controlling the deposition time and direction (down face or up face) of $\mathrm{ZnO} / \mathrm{SiO}_{2} / \mathrm{Si}$ substrates.

Figure 6 shows the XRD spectra of the $3 \mathrm{~h}$ deposited $\mathrm{ZnO}$ films prepared at different faces. Results indicate that down-face $\mathrm{ZnO}$ films only had a strong (002) peak and up-face $\mathrm{ZnO}$ films had a strong (002) peak and two weak (100) and (110) peaks preferred orientation with the $c$-axis perpendicular to the substrate. All the (002) peaks in Figure 6 were found at $2 \theta \sim 34.45^{\circ}$, which was the same as the stoichiometric $\mathrm{ZnO}$ crystal $\left(2 \theta \sim 34.45^{\circ}\right)$. These results imply that the parameter of lattice constant $c$ is unchanged as different faces of $\mathrm{ZnO} / \mathrm{SiO}_{2} / \mathrm{Si}$ substrates are used in the synthesizing process. The results for XRD patterns of the $\mathrm{ZnO}$ films in Figures 4 and 6 can be described as a number of alternating planes composed of tetrahedrally coordinated $\mathrm{O}^{2-}$ and $\mathrm{Zn}^{2+}$ stacked alternately along the $c$-axis. Also, the $\mathrm{ZnO}$ films exhibit a varied range of novel structures. These structures can be grown by tuning the growth rates along different fast growing directions. As those results in SEM images and XRD patterns, changing the face of the $\mathrm{ZnO} / \mathrm{SiO}_{2} / \mathrm{Si}$ substrates will change the nucleation mechanisms and then change the synthesizing results of the $\mathrm{ZnO}$ films, because homogenous nucleation produces undesired $\mathrm{ZnO}$ particles and heterogeneous nucleation produces nanorods. As the $\mathrm{ZnO}$ seed layer is grown on the $\mathrm{SiO}_{2} / \mathrm{Si}$ substrates, we think the irregular-plate type $\mathrm{ZnO}$ is grown under the heterogeneous nucleation, which is much more common than homogeneous nucleation. Heterogeneous nucleation is typically much faster than homogeneous nucleation because the nucleation barrier $\left(\Delta G^{*}\right)$ is much lower at a surface. For that, the irregular-plate type $\mathrm{ZnO}$ is grown first. However, $\mathrm{ZnO}$ nanorods are limited by homogenous nucleation of $\mathrm{ZnO}$ particles that align the $c$-axis and $\mathrm{ZnO}$ nanoflowers are homogenous nucleation in a different crystalline direction as the nanorods are grown too long.

\section{Conclusions}

As the synthesized time was $1 \mathrm{~h}, 3 \mathrm{~h}$, and $5 \mathrm{~h}$, the downface morphologies of $\mathrm{ZnO}$ films on $\mathrm{ZnO} / \mathrm{SiO}_{2} / \mathrm{Si}$ substrates were irregular-plate structure films, $\mathrm{ZnO}$ nanorods with a diameter ranging from 65 to $200 \mathrm{~nm}$, and beautiful chrysanthemum- (flower-) like clusters grown above the nanorods in very large quantity, respectively. As the synthesized time was $1 \mathrm{~h}, 3 \mathrm{~h}$, and $5 \mathrm{~h}$, the pure $\mathrm{ZnO}$ nanorods could not be obtained in up-face $\mathrm{ZnO}$ films. XRD patterns indicated that $1 \mathrm{~h}$ and $5 \mathrm{~h}$ deposited $\mathrm{ZnO}$ films had a (002) peak and two weak (100) and (110) peaks and $3 \mathrm{~h}$ deposited $\mathrm{ZnO}$ films only had a strong (002) peak. The reason for different morphologies of the $\mathrm{ZnO}$ films obtained on the two faces should be related to the two nucleation mechanisms, heterogeneous nucleation and homogenous nucleation, in the solution. As deposition time was $3 \mathrm{~h}$, the down-face morphology of $\mathrm{ZnO}$ films was only $\mathrm{ZnO}$ nanorods with a diameter ranging from 65 to $200 \mathrm{~nm}$ and in very large quantity, which could be investigated as gas sensors.

\section{Conflict of Interests}

The authors have no financial competing interests.

\section{Acknowledgments}

The authors acknowledge financial supports of NSC 102-2221E-218-036, NSC 102-2622-E-390-002-CC3, and NSC 1022221-E-390-027. 


\section{References}

[1] F. H. Wang, C. F. Yang, and Y. H. Lee, "Deposition of F-doped $\mathrm{ZnO}$ transparent thin films using $\mathrm{ZnF}_{2}$-doped $\mathrm{ZnO}$ target under different sputtering substrate temperatures," Nanoscale Research Letters, vol. 9, article 97, 2014.

[2] J. Chung, J. Lee, and S. Lim, "Annealing effects of $\mathrm{ZnO}$ nanorods on dye-sensitized solar cell efficiency," Physica B, vol. 405, no. 11, pp. 2593-2598, 2010.

[3] N. Saito, H. Haneda, T. Sekiguchi, N. Ohashi, I. Sakaguchi, and K. Koumoto, "Low-temperature fabrication of light-emitting zinc oxide micropatterns using self-assembled monolayers," Advanced Materials, vol. 14, no. 6, pp. 418-421, 2002.

[4] G. Kwak, M. Seol, Y. Tak, and K. Yong, "Superhydrophobic znO nanowire surface: chemical modification and effects of UV irradiation," Journal of Physical Chemistry C, vol. 113, no. 28, pp. 12085-12089, 2009.

[5] L. Wang, Y. Kang, X. Liu, S. Zhang, W. Huang, and S. Wang, "ZnO nanorod gas sensor for ethanol detection," Sensors and Actuators, B: Chemical, vol. 162, no. 1, pp. 237-243, 2012.

[6] L. Li, H. Yang, H. Zhao et al., "Hydrothermal synthesis and gas sensing properties of single-crystalline ultralong $\mathrm{ZnO}$ nanowires," Applied Physics A, vol. 98, no. 3, pp. 635-641, 2010.

[7] J. Kim and K. Yong, "Mechanism study of $\mathrm{ZnO}$ nanorod-bundle sensors for $\mathrm{H}_{2} \mathrm{~S}$ gas sensing," Journal of Physical Chemistry $C$, vol. 115, no. 15, pp. 7218-7224, 2011.

[8] H. Ghayour, H. R. Rezaie, S. Mirdamadi, and A. A. Nourbakhsh, "The effect of seed layer thickness on alignment and morphology of ZnO nanorods," Vacuum, vol. 86, no. 1, pp. 101-105, 2011.

[9] X. Jiaqiang, C. Yuping, C. Daoyong, and S. Jianian, "Hydrothermal synthesis and gas sensing characters of $\mathrm{ZnO}$ nanorods," Sensors and Actuators, B: Chemical, vol. 113, no. 1, pp. 526-531, 2006.

[10] L. Vayssieres, "Growth of arrayed nanorods and nanowires of $\mathrm{ZnO}$ from aqueous solutions," Advanced Materials, vol. 15, no. 5, pp. 464-466, 2003.

[11] G. Kenanakis, D. Vernardou, E. Koudoumas, and N. Katsarakis, "Growth of c-axis oriented $\mathrm{ZnO}$ nanowires from aqueous solution: The decisive role of a seed layer for controlling the wires' diameter," Journal of Crystal Growth, vol. 311, no. 23-24, pp. 4799-4804, 2009.

[12] X. Liu, Z. Jin, S. Bu, J. Zhao, and Z. Liu, "Effect of buffer layer on solution deposited $\mathrm{ZnO}$ films," Materials Letters, vol. 59, no. 29-30, pp. 3994-3999, 2005.

[13] V. L. Snoeyink and D. Jenkins, Water Chemistry, John Wiley \& Sons, 1980.

[14] Z. Li, X. Huang, J. Liu, Y. Li, X. Ji, and G. Li, "Growth and comparison of different morphologic $\mathrm{ZnO}$ nanorod arrays by a simple aqueous solution route," Materials Letters, vol. 61, no. 22, pp. 4362-4365, 2007. 

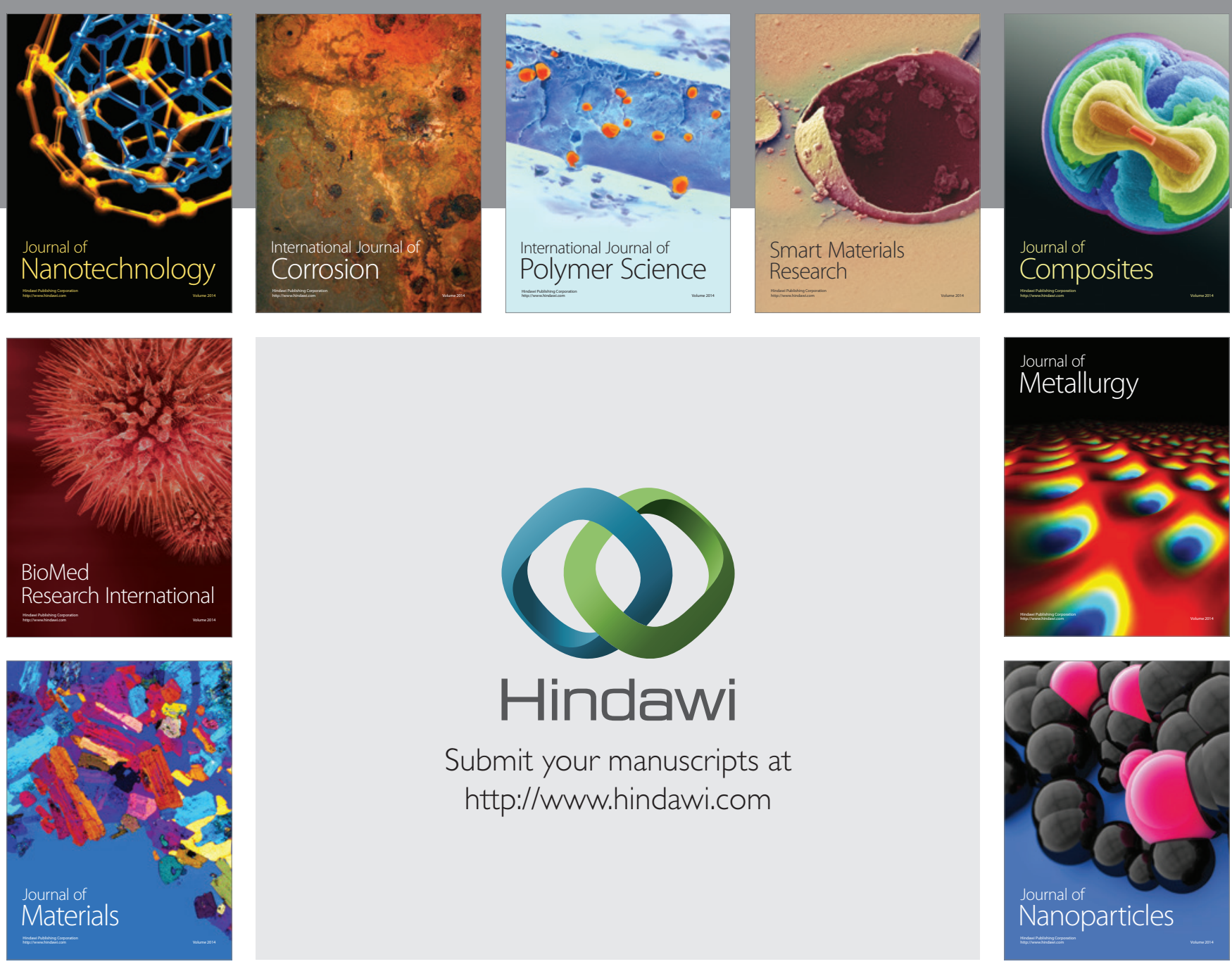

Submit your manuscripts at http://www.hindawi.com
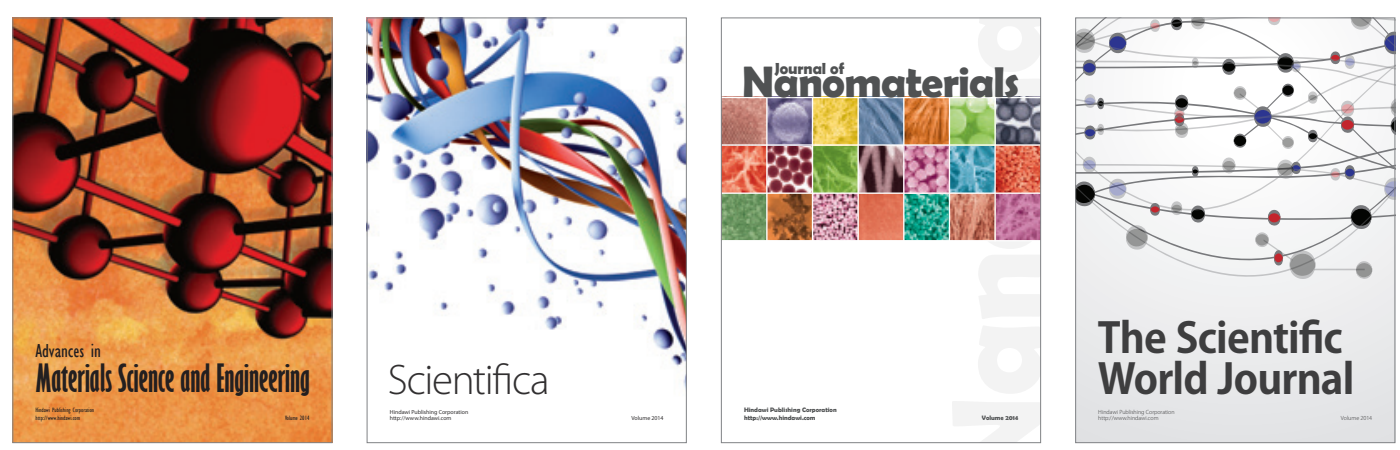

\section{The Scientific World Journal}
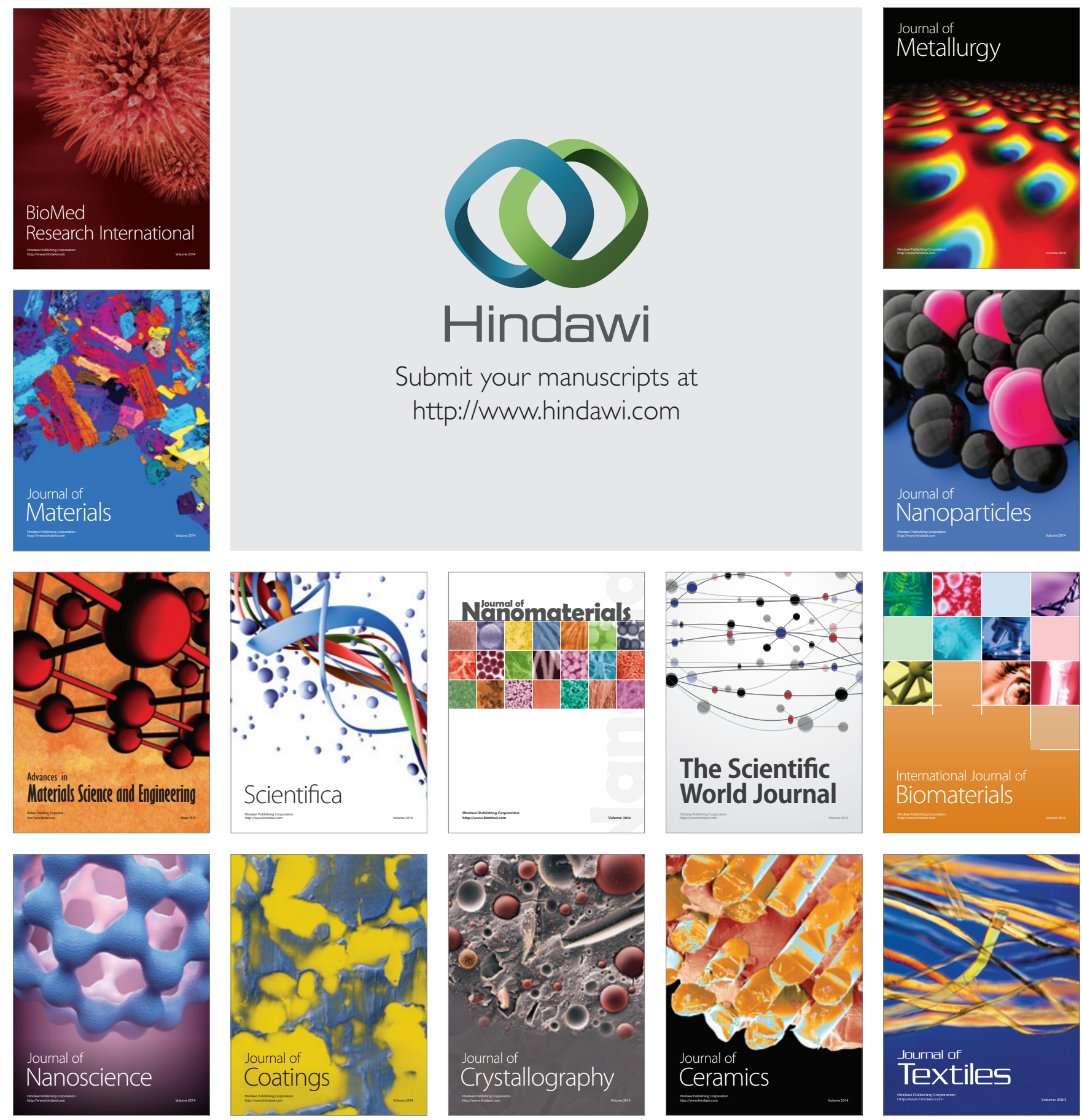